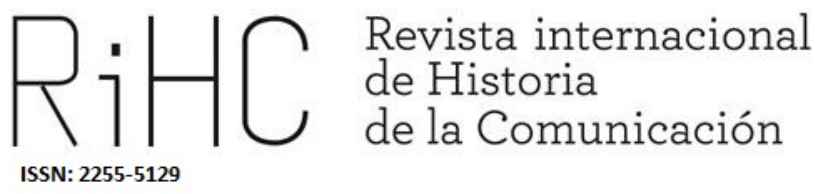

\title{
A RTP EM AMBIENTE DIGITAL: DOS ANOS 90 À ATUALIDADE - UM ENQUADRAMENTO TEÓRICO
}

RTP in a digital environment: from the 90s to the present - a theoretical framework

DOI: http://dx.doi.org/10.12795/RiHC.2019.i13.02

Recibido: 15/10/2019

Aceptado: 6/12/2019

Publicado: $15 / 12 / 2019$

Francisco Rui Cádima

ORCID (iD) 0000-0002-5449-8831

Universidade Nova de Lisboa, Portugal

frcadima@fcsh.unl.pt 
Resumo: Neste artigo vamos procurar aprofundar um conjunto de questões relativas ao estado da arte e de enquadramento teórico que nos permitiu fazer a contextualização e a análise da evolução do website da RTP ao longo dos últimos vinte anos (1998-2018). O presente artigo integra, portanto, essencialmente, um contexto teórico e uma dimensão analítica sobre esse corpus. Finalizamos com uma abordagem das questões de preservação e de política de arquivo para a Web dado que constatámos nesta pesquisa que um importante património se tem vindo a perder consecutivamente, e se continuará a perder se não forem tomadas medidas assertivas nesta matéria. Este artigo é também um alerta para essa perda dramática de conteúdos online que se verifica desde a criação da Web.

Palavras-chave: Televisão, Web, Internet, Preservação, Arquivo

\begin{abstract}
In this paper we will look to deepen into a set of state of the art and theoretical framework issues that allowed us to contextualize and analyze the evolution of the RTP website over the last twenty years (1998-2018). Therefore, this article essentially integrates an analytical dimension and a theoretical context on this corpus. We end it with an approach to the preservation and an archival policy for the Web, as we have found in the research that a significant heritage has been consecutively lost and will continue to be lost if no assertive action is taken on this issue. This paper is also a warning for this dramatic loss of online content that occurs since the creation of the Web.
\end{abstract}

Keywords: Television, Web, Internet, Preservation, Archive

\title{
1 Introdução
}

Procuraremos neste artigo sistematizar um conjunto de dados e estudos disponíveis que nos permitam estruturar uma genealogia e um enquadramento teórico para avaliar as características do serviço da RTP em matéria de conteúdos online, quer subordinados à programação de televisão propriamente dita, quer relativamente aos novos serviços para plataformas digitais e Internet.

Começaremos justamente por invocar os poucos trabalhos anteriores conhecidos, onde nós próprios e outros investigadores portugueses e estrangeiros foram desenvolvendo análises diversas, com metodologias semelhantes, que nos permitem agora fazer uma primeira avaliação dessa breve arqueologia, especificamente sobre o tema em apreço. Procuraremos fazer esta apresentação dos dados existentes de forma essencialmente cronológica, retomando as principais linhas conclusivas a que se foi chegando nesta matéria. 


\section{Estado da arte}

Num primeiro estudo desenvolvido sobre a especificidade dos conteúdos culturais do sistema público nacional e de algumas das suas principais instituições em geral, foi então feita uma primeira abordagem aos websites dos media públicos portugueses existentes à data. As conclusões que então retirámos relativamente ao ainda embrionário website da RTP (Cádima, 2000), foram essencialmente as seguintes: na página de abertura - http://www.rtp.pt, acedíamos às grandes áreas do site, isto é, Programação, Destaques, Informação em Real Vídeo, Teletexto e Outra Informação. $\mathrm{Na}$ Programação (http://www.rtp.pt/prog/lyprog.htm) encontrávamos as grelhas diárias da RTP1 e da RTP2 e alguns destaques. Na Informação em Real Vídeo (http://www.rtp.pt/telejornal/lytelej.htm) podia escolher-se o dia da semana em que se pretendia ver o Telejornal online, ainda que com problemas técnicos de acesso nas várias tentativas feitas. Era ainda possível aceder aos sites de outros canais da RTP (RTPi, RTP África, RTP Açores e RTP Madeira), bem como ao site da TV Guia e da RTC, ao serviço de última hora Press Line (http://www.rtp.pt/pressline/lypress.htm), com informação sobre programas em produção, últimas estreias, havendo também um link para o Telejornal em vídeo através de Real Player. Em síntese:

“Para além de uma apreciação estética do site, que denota desde logo pouca homogeneidade global, nesta presença da RTP na net, o grau de interactividade relativamente aos conteúdos é ainda muito reduzido, tendo-se registado uma impossibilidade técnica de aceder ao Telejornal online quando por diversas vezes se pretendeu aceder às principais peças do Telejornal da véspera. Do nosso ponto de vista é precisamente neste âmbito do acesso aos conteúdos televisivos que nos parece haver uma das maiores lacunas do site, na medida em que ainda não é possível o visionamento de outros programas do arquivo da RTP, arquivo histórico ou mesmo arquivo mais recente (...)." (Cádima, 2000: 188).

Um dos pontos relevantes que analisámos também neste estudo foi a questão do Arquivo da RTP, que tem relevância para a presente contextualização. A Direção de Arquivos e Documentação da Radiotelevisão Portuguesa (RTP) tinha, à data, como principais competências, assegurar a gestão arquivística dos fundos documentais existentes da RTP e ainda garantir o acesso público àqueles fundos, ainda que com diversas restrições inadequadas a um serviço público online, facto que viria a ser mais recentemente ultrapassado com o acesso disponível através da Internet. Sabia-se que a RTP tinha já iniciado processos de digitalização do seu arquivo, muito embora não tivéssemos uma ideia clara da dimensão do trabalho realizado à data, no ano 2000, nos três tipos de arquivos existentes (fotográfico, audiovisual e bibliográfico/documental). Segundo o nosso levantamento junto da empresa, os arquivos estavam então subdivididos em fotográfico, com 240 mil peças, e audiovisual, com 330 mil peças dispersas por diversos tipos de suportes (filme $16 \mathrm{~mm}$ 
negativo/internegativo, Vídeo/Analógico PAL, vídeo digital e microfilmes). Alguns projetos de restauro estavam em implementação, havendo a referir o programa Aurora (Automated Restoration on Original Film and Video Archives), aplicado na RTP durante a Expo'98, com a recuperação de várias horas de arquivos documentais televisivos sobre o tema dos oceanos, e ainda parcerias pontuais com o ANIM-Arquivo Nacional de Imagens em Movimento para a recuperação pontual de sequências em película.

Foram identificados também projetos de digitalização em curso para uma maior facilitação da consulta para rede interna (dois projetos em Intranet) e outro para acesso público (Internet). Foram-nos ainda referidos à época os Projetos Vidion Digital, que disponibilizaria para consulta cerca de 5 mil horas de material informativo e desportivo recente e a Emissão RTP 1 e RTP 2 para verificação, descrição de conteúdos de Arquivo e Estatística; e o Projecto Alert (Alert System for Selective Dissemination of Multimedia Information), projeto este que visava disponibilizar um sistema de Difusão Seletiva de Informação Multimédia. Esperava-se, entretanto, a partir do ano 2000, um aumento de produções já em formato digital a partir da produção de informação baseada num Centro de Emissão digital e com suporte de vídeo-servers e uma futura operacionalização da infraestrutura do Arquivo Digital desenvolvido no âmbito de um projecto PRAXIS XXI: Vidion - Vídeo Digital On-line.

De acordo com António Granado (2002), a RTP foi o primeiro meio de comunicação social português a registar oficialmente o seu domínio, justamente em 28 de Maio de 1993 (rtp.pt), sendo que em Novembro de 1995 a RTPi inaugurava a sua página na Internet. Desde então, e baseando-nos na periodização proposta por Hélder Bastos (2010) específica dos websites com informação jornalística, mas que é relevante também para esta nossa análise pela sua exclusividade, podem identificar-se três grandes períodos na história do jornalismo português online, muito embora não se trate de períodos absolutamente estanques, dada a diversidade de situações então existentes: i) o período de 1995-1998, de implementação, que corresponde à criação dos primeiros websites dos media; ii) uma segunda fase (1999-2000) considerada de "expansão", em que se verifica uma forte aposta dos media tradicionais no digital; e a terceira (2001-2010) intitulada como de "depressão", esta sobretudo associada ao facto de muitos dos investimentos bastante significativos então feitos em Portugal não terem gerado qualquer tipo de rentabilidade, ou trazido novos públicos, pelo que houve uma clara recessão no modelo de migração com o fecho de alguns portais que haviam gerado algumas expectativa por parte dos grupos de media (veja-se por exemplo o caso do portal da Abril/Controljornal - o Directo.co.pt).

Ora, convirá acrescentar a este quadro uma outra proposta (Cunha, 2017) que nos sugere que no início, ainda nos anos 90, há um modelo de migração e publicação digital que podemos referir como "shovelware", de mera reprodução do que se fazia 
no analógico, passando-se a uma fase de adaptação ao digital em que são introduzidas hiperligações e peças multimédia ainda com os conteúdos muito próximos dos media tradicionais, sendo que no final da década de 1990 se verifica uma clara ruptura com uma cada vez maior atualização dos conteúdos para a Net, podendo chamar-se a esta fase a da "web first".

De referir, ainda, as conclusões de Fernando Zamith (2008) com a sua avaliação da situação genérica dos media online portugueses cerca de 10 anos após o arranque do ciberjornalismo em Portugal, em que este investigador considerava, a partir de uma grelha de análise de conteúdos, que eram ainda algo limitadas as opções utilizadas pelos meios online não chegando a um quarto das potencialidades disponibilizadas pela nova tecnologia: "O nível de aproveitamento global das potencialidades da Internet situa-se em $21,5 \%$ nos conteúdos e dispositivos de acesso livre, que constitui o tipo de acesso claramente dominante (92\%). Juntando os conteúdos e dispositivos acessíveis mediante registo gratuito, o nível de aproveitamento sobe ligeiramente para 22,2\%." (Zamith, 2008: 182). Para este investigador, o jornal Público, com 43\%, era então a publicação online que tirava maior partido das potencialidades ciberjornalísticas da Internet, seguindo-se o Portugal Diário e a RTP, respetivamente com $38 \%$ e $36 \%$. No conjunto, se a multimedialidade (áudio, vídeo, imagem fixa, infografia) era uma das categorias que ultrapassava a média, com 26,5\%, uma outra das categorias centrais neste processo - a interatividade - não passava dos 17,5\%, 0 que para o autor confirmava a "grande distância" a que os ciberjornais 'mainstream' mantinham visitantes e utilizadores no contexto do processo de produção de informação, facilitação de e-mail dos jornalistas, disponibilização de fóruns de discussão, salas de "chat", blogs ou wikis aberto à participação do público, etc., de forma a que os leitores pudessem integrar mais facilmente o processo de interação com a redação.

Entre as obras que nos ajudam a compreender todo o contexto em que os media públicos, nomeadamente, foram desenvolvendo as suas estratégias para a Internet, está o estudo de Tânia de Morais Soares (2006), intitulado “Cibermedi@: Os Meios de Comunicação Social Portugueses Online", baseado na sua tese de mestrado sobre a presença online dos meios de comunicação social portugueses, procurando analisar, em particular, fatores de mudança associados ao âmbito específico da informação televisiva online. O estudo abarca um conjunto alargado de meios de comunicação social portugueses no início do seu processo de migração para o digital, sobretudo no período entre 1998 e 2003, sendo que, relativamente ao período 1998-2000 a obra inclui dados obtidos no contexto do Projecto Ciberfaces: A Sociedade de Informação em Análise - Internet, Interfaces do Social, do Programa PRAXIS XXI da FCT, desenvolvido por uma equipa de investigação coordenada por José Manuel Paquete de Oliveira e por José Jorge Barreiros, ambos do ISCTE. 
De acordo com a autora, "Os meios de comunicação social portugueses online evoluíram, entre 1999 e 2003, na tomada de consciência relativamente à necessidade de criar interfaces com o seu público electrónico, conferindo a este a sensação de poder interagir com os conteúdos e com os emissores e rentabilizando a capacidade de identificar e fidelizar esse mesmo público" (Soares, 2006: 225), reconhecendo, muito embora, que já então era observável que as características sociográficas do público dos media online eram diferenciadas face aos dos media tradicionais.

Outra tendência observável neste contexto emergente de migração para o digital pela autora prendia-se com a recolha de dados, opiniões, comentários, com o objetivo de registar e fidelizar os novos "consumidores online" tendo em vista as estratégias de viabilização económica dos novos serviços. Neste caso, verificava-se já a existência de publicidade comercial em geral e também de publicidade mais direcionada para bens culturais, indústrias culturais em geral, ou para as áreas tecnológicas, de lazer, turismo, etc. Sob o ponto de vista da apresentação e organização da informação, usabilidade dos interfaces, etc., a autora considerava que o modelo era em geral muito "analógico", baseado no modelo clássico dos jornais: "o facto é que a maioria das páginas Web de televisões, jornais, revistas e algumas de rádio, se aproximam verdadeiramente da lógica do jornal tradicional, ao organizarem os seus conteúdos seguindo as suas categorias e o seu padrão, e ao recorrerem ao texto escrito e à imagem estática como forma dominante de disponibilização de informação" (Soares, 2006: 229-230). E acrescentava:

"O meio líder que domina tradicionalmente em termos de audiência e em termos de lançar a agenda do dia dos media que os outros seguirão, que é a televisão, surge agora online subordinado às formas de apresentação e organização da informação mais próxima das lógicas da imprensa escrita, dandose, num suporte que é multimédia, uma clara dominação do texto escrito como modo fundamental de comunicação. A incorporação de suportes existe, o texto, a imagem e o som aparecem integrados na Internet. Mas, em termos de organização formal das páginas, as lógicas, as categorias e o modo de comunicação escrito parecem liderar novamente. Aquilo que parecia estar a perder audiência - "a escrita", dita agora as regras na última das novidades tecnológicas." (Soares, 2006: 230).

O diagnóstico então produzido por Tânia de Morais Soares aborda também a questão comparativa entre imprensa e meios audiovisuais. Este aspeto é relevante porque é justamente a imprensa, meio mais tradicional, que parece adaptar-se melhor, nesta primeira fase da migração, às exigências do digital. Curiosamente era entre os jornais que se encontram as páginas Web mais desenvolvidas. Pelo contrário, os media audiovisuais, como as páginas de televisão e de rádio, apresentavam-se com características menos definidas "parecendo por isso modelos mais provisórios e menos 
instalados do que os dos jornais." (Soares, 2006: 231). Daí que a análise dos meios televisivos refira também um "acentuar da negligência face à função entretenimento na maioria dos media online, remetida agora para um plano secundário, quando no suporte tradicional e, nomeadamente, na televisão tradicional offline, ela se assume como a rainha dos géneros televisivos" (Soares, 2006: 230). Em síntese, se, por um lado, os media portugueses legitimavam, de certo modo, as novas estratégias para o online sobre uma relação de credibilidade de que a imprensa em geral sempre desfrutou relativamente às suas audiências, por outro lado, estavam "claramente a inserir-se em lógicas de apresentação na Internet mediadas por representações clássicas ou tradicionais, inerentes às próprias características dos meios de comunicação (2006: 233).

De um modo geral podemos concluir, no âmbito desta análise, que houve uma evolução positiva dos meios de comunicação social portugueses online ao longo deste primeiro período aqui em análise (1998-2003) e, depois, com Zamith (2006-2007), passando-se de uma fase em que tipicamente importava estar online, a par dos concorrentes, e seguindo a tendência internacional, para uma fase intermédia em que eram já patentes objetivos mais exigentes, quer do ponto de vista da produção de conteúdos de informação, usabilidade, grafismos e estrutura geral das páginas, quer ainda no plano do acesso à emissão online (sobretudo na rádio), acesso a arquivo e inclusive alguns modelos embrionários de interatividade.

\section{Para uma análise da TV online em Portugal}

Vejamos agora uma outra análise, posterior a estas últimas, de Fernando Zamith e de Tânia Soares, em que pretendíamos fazer um ponto de situação relativamente à evolução entretanto ocorrida nos websites dos canais da televisão pública existentes na Web. Do nosso ponto de vista, em particular a evolução dos websites "televisivos" desde finais dos anos 90 não registava dinâmicas substancialmente diferentes daquelas que seria expectável prever dez anos antes, tendo em conta o modelo da RTP que considerávamos então "insuficiente", isto porque não se compaginava de todo com atribuições e competências que se exigiam ao operador público nos ambientes web emergentes. Dez anos volvidos, o website da RTP consolidava-se progressivamente, muito embora se continuassem a verificar problemas já identificados no passado. Uma frágil afirmação da cidadania e das atribuições e competências do operador público, por exemplo a emissão online era habitualmente a da RTPN. Verificava-se também uma secundarização da área de vídeo, num movimento contrário ao que se estava a observar nos sites dos media escritos, onde o 
acesso aos players e a ficheiros vídeo ganhavam uma importância cada vez maior nas páginas principais dos media. Outra questão era a insuficiência da informação sobre os próprios programas em destaque, por vezes dando só o título ou o tema do programa como sucedia em regra com o Prós e Contras. Ou a indisponibilidade de sistemas de comunicação interactiva entre os editores e/ou jornalistas e os cidadãos e/ou telespectadores. E também a "reduzida disponibilidade de arquivo em consulta aberta, limitada a um conjunto restrito de programas recentes" Cádima (2008: 107), portanto a indisponibilidade de conteúdos do arquivo histórico da RTP. Pensávamos então que "aquilo que se espera dos novos media (...) emergentes será a construção de um modelo de comunicação que se venha a configurar como estruturante na consolidação de um novo projecto da experiência democrática" (Cádima, 2008), e a verdade é que, curiosamente, esse viria a ser o princípio prevalecente da Communication Broadcasting Communication (2009) da Comissão Europeia, quando esta referia que importava manter os conteúdos do Public Service Media (PSM) relevando prioritariamente das necessidades democráticas, sociais e culturais da sociedade, que vinha ao encontro também da Comunicação da CE (2001) sobre os auxílios estatais ao serviço público.

Outro tipo de avaliação que foi já feita no passado e que importa ter agora presente e que tem tido desenvolvimentos recentes -, prende-se com o estado da acessibilidade dos conteúdos Web à luz das WCAG do W3C (Web Content Accessibility Guidelines, do World Wide Web Consortium (ERC, 2014). Sobre este ponto mais específico veja-se ainda a DIRETIVA (UE) (2016) relativa à acessibilidade dos sítios Web e a tese de Carlos Raposo (2017). Vamos basear-nos, essencialmente, no estudo pioneiro da autoria de Jorge Fernandes (2011), onde, após uma análise aos conteúdos de primeira página dos websites das televisões generalistas portuguesas se começava por concluir genericamente o seguinte:

"Os conteúdos da TVI são os que melhor respondem aos requisitos de acessibilidade do World Wide Web Consortium (W3C). A afirmação condicional não é mero efeito estilístico literário. Na verdade, fruto de estudos anteriores, o melhor dos resultados, o da TVI, se relativamente é o melhor dos 3, em termos absolutos ele não reflete uma prática excecional. Afinal nenhum dos sítios analisados do lote da imprensa televisiva lograram sequer alcançar o nível mínimo de conformidade do W3C: o nível de conformidade A." (Fernandes: 2011: 9).

Basicamente, no que diz respeito ao telejornalismo online das três televisões generalistas portuguesas, e em particular ao caso da RTP, que no presente contexto mais nos interessa, e começando justamente pelo menu principal, era referido que a RTP optava então, no período em análise (Março a Agosto de 2011), por um menu principal em "painel", que são em geral menus bastante "pesados", declinando depois, 
em simultâneo, múltiplas opções ao utilizador. Ora, de acordo com a análise feita, desaconselhava-se o uso de painéis para cada uma das opções do menu principal dado tratar-se de uma técnica que gerava menus enormes, difíceis de gerir, o que dificultava, portanto, as questões de acessibilidade: "Num sítio Web grande é fundamental cuidar da estrutura da informação para dar a possibilidade aos utilizadores de tecnologias de apoio a possibilidade de saltar por listas, cabeçalhos, parágrafos, tabelas, formulários, imagens, etc. A estrutura enriquece as possibilidades de navegação pelas páginas." (Fernandes, 2011: 13).

Outros problemas identificados no estudo: i) inserção no website de "molduras de informação" de terceiros sem padrões de acessibilidade (módulos directos do Facebook via iframe, ou informação da meteorologia e trânsito via javascript); ii) links não encontrados, vídeos que não funcionam, motores de busca bastante fracos; iii) as dificuldades de utilização do vídeo por pessoas com deficiência (os vídeos propriamente ditos e a interface do player que permite controlar o vídeo) estando baseado em Flash não permitia o uso do teclado, sendo então fundamental aqui, por um lado, o uso de players que sejam controláveis com rato e com teclado, e, por outro, a disponibilização de alternativas à imagem e ao som: legendagem, língua gestual portuguesa, audiodescrição - veja-se neste caso em particular o Estudo sobre a recepção de audiodescrição (2016), e mesmo transcrição textual - o que no caso da RTP1 sucedia com o programa Bom Dia Portugal e com o Jornal da Tarde quando repetia à tarde na RTP2. Claramente positivo era o facto de o website da RTP ter uma funcionalidade de acessibilidade relevante que permitia a leitura de artigos através de um sintetizador de fala em Português, considerado de "alta qualidade" e ainda o facto de estar a ser então já desenvolvido entre RTP, Priberam e INESC-ID, um motor de busca avançado para pesquisas de informação nas peças de vídeo. Nenhum operador disponibilizava então programas online com legendagem. "A LGP (Língua Gestual Portuguesa) é o único equivalente alternativo que marca presença online. Contudo tem a desvantagem de ser uma cópia do vídeo que passa em televisão. Deveriam de "descolar" o frame de LGP e dar-lhe, no mínimo, metade do ecrã." (Fernandes, 2011: 17). Numa rápida síntese sobre a RTP, no âmbito da avaliação do website associado ao registo televisivo, o estudo de Jorge Fernandes apontava a RTP como pioneira no uso do símbolo de acessibilidade e o único também com uma página a descrever as funcionalidades de acessibilidade disponíveis na Web e na emissão televisiva.

Outras investigações a que faremos referência prendem-se com pesquisas relacionadas com formação avançada, nomeadamente teses de mestrado. Veremos, em primeiro lugar, a tese de mestrado em Novos Media e Práticas Web de Sónia Santos Dias (NOVA FCSH, 2010) intitulada "Web TV - Análise e melhores práticas em OCS nacionais e internacionais". Os objetivos deste trabalho de projeto eram, nomeadamente, analisar vídeos e Web TV dos media e as reportagens em vídeo realizadas especificamente para a Internet e também identificar as melhores práticas a 
serem utilizadas numa Web TV; problematizar as estratégias adotadas pelos media na disponibilização de conteúdos de informação na Internet tendo em atenção o carácter jornalístico dos conteúdos colocados online. Dado que, nomeadamente a RTP, o nosso estudo de caso, não pôde ser considerada no âmbito desta investigação de mestrado, uma vez que não produzia à altura informação em exclusivo para a Net, não considerámos, portanto, as conclusões desta tese neste nosso trabalho. Uma outra tese, esta sim com dados relevantes para este nosso enquadramento, é a de Diana Bernardo, intitulada "As Televisões generalistas portuguesas online - Estudos sobre a presença de conteúdos informativos nos sites da RTP, SIC e TVI" (ESCS, 2012). Neste caso, Diana Bernardo faz uma avaliação qualitativa dos websites das televisões generalistas portuguesas procurando analisar diferentes parâmetros, nomeadamente o número de peças diárias, respetiva categoria, recurso a elementos de áudio, vídeo e fotografia, hiperligações, atualizações, etc.

Complementarmente, são aplicadas metodologias inicialmente desenvolvidas por Schultz (1999) e posteriormente atualizadas por Zamith (2008), avaliando outras dimensões, a saber: a interatividade, a hipertextualidade, a multimedialidade, a instantaneidade, a ubiquidade, a memória, a personalização e a criatividade. Também de acordo com os resultados apresentados por Diana Bernardo a RTP posicionava-se ligeiramente acima das suas concorrentes privadas: "A conclusão mais evidente a tirar destes resultados é que apenas a RTP ultrapassa metade da pontuação máxima possível (100), com 58 pontos. Todos os outros sites analisados situam-se aquém desse valor, o que demonstra que não estarão a utilizar todas as potencialidades que a web oferece" (Bernardo, 2012: 37). Entre os principais aspetos a serem melhorados, encontramos claramente a questão da pesquisa em arquivo e o problema do aprofundamento da interatividade, designadamente entre os jornalistas e o seu público, uma velha pecha da profissão há muito identificada em estudos idênticos e que ainda nos dias de hoje não está resolvida.

Para além dos objetivos estarem centrados no modelo mais tradicional de website, são agora identificadas também novas aplicações estratégicas por parte de todos os operadores de televisão generalistas como, nomeadamente, a mobile TV e as redes sociais. As versões de mobile TV são, no entanto, consideradas relativamente pobres quando comparadas com as aplicações para Smartphone. Em relação às redes, a RTP surgia com várias páginas no Facebook e contas no Twitter associadas a vários canais, a programas em específico e à própria redação, como era o caso da conta “@rtpnoticias”, gerida pela redação multimédia da RTP. Após a análise das notícias disponibilizadas nos sites da RTP, SIC e TVI ao longo de um período de sete dias, Diana Bernardo apresenta os seguintes resultados relevando ainda o facto de a RTP potenciar recursos vídeo, e também deter a área da Rádio, o que sucedia menos com SIC e TVI, que se limitam mais ao formato tradicional da informação: 
“(...) A TVI produz um número de notícias maior que a RTP e, sobretudo, que a SIC, sendo que esta última aparece como a marca que menos notícias disponibiliza online. No geral, as notícias começam a ser disponibilizadas nos sites por volta das 7h/8h da manhã (a RTP é o operador que tem a informação disponível mais cedo) e continuam, regularmente, até cerca da meia-noite (um pouco mais cedo na RTP). (...) A RTP é o operador cujo site faz mais uso de conteúdos de vídeo, $58 \%$ das notícias produzidas têm vídeos que as acompanham, sendo que esses vídeos são quase exclusivamente transposições das notícias emitidas nos serviços informativos do canal (contendo, algumas vezes, até a parte do pivot). (Bernardo, 2012: 51).

No quadro dos estudos já referidos, aquele que, entretanto, veio acrescentar algum valor ao atual estado da arte é o relatório de Diogo Cunha (2017) sobre as transformações da presença dos jornais portugueses na Web (1996-2016). A partir do portal Arquivo.pt, que permite fazer pesquisas exaustivas da Web portuguesa desde 1996 (por endereço, por termo, etc.), Cunha desenvolveu um interessante projeto de investigação em torno da análise da evolução dos websites de jornais portugueses nos últimos 20 anos, trabalhando parâmetros diversos como por exemplo a arquivabilidade do website, o estado técnico atual de preservação digital, a evolução das versões, dos layouts, etc. Não abordando o caso da RTP, consideramos, apesar disso, o interesse deste estudo no âmbito do nosso estudo. Veja-se, para o caso, o eloquente exemplo da questão da preservação digital (que envolve questões de acessibilidade, coesão, meta-dados e conformidade de padrões). A análise feita através do sistema ArchiveReady deu os seguintes resultados (22/7/2017): cmjornal.pt - 79\%; dn.pt - 62\%; expresso.sapo.pt -56\%; e publico.pt - 64\%. Significa que os media fazem, fundamentalmente, uma acumulação descontrolada da informação que geram, deitando a perder todo o seu valioso património. De acordo com o autor, CM, DN, Expresso e Público "não têm uma cultura de preservação digital desenvolvida e informada, nem possuem políticas de preservação digital estruturadas. Graças a isso, o que esteve nos seus websites pode estar perdido para sempre e o que ainda neles se encontra pode estar prestes a perder-se. Parece assim justificar-se que se fale de problemas de memória no jornalismo português". (Cunha, 2017: 49). Ora, como bem sintetiza o autor no seu estudo:

"Estas evidências mostram que a ideia de "arquivo" dos jornais está ainda muito focada num modelo de shovelware e que, ainda assim, nem todos os materiais impressos dos jornais foram digitalizados e disponibilizados nos respectivos websites. Quanto aos conteúdos dos websites propriamente ditos, nada garante que estão todos nos websites visto que não há colecções dos conteúdos dos websites organizadas. Mais claro é o facto de que muito embora alguns desses conteúdos mais antigos (não parece haver nada anterior a 2000), até possam estar nos websites, os websites actuais não reproduzem as condições de leitura 
digital que os websites onde tais conteúdos foram primeiramente colocados tinham." (Cunha, 2017: 47).

Interessante é também a análise das diferentes versões de endereços que foram sendo criadas ao longo dos últimos 20 anos. No primeiro levantamento do investigador, os resultados conseguidos aparentavam já ter uma relevância significativa, mas verificouse, entretanto, que pecavam por defeito: A primeira análise da evolução dos media portugueses feita até 2015 sugeria os seguintes valores: Correio da Manhã - 19962015: 1016 versões; Diário de Notícias - 2001-2015: 783 versões; Público - 2005-2015: 630 versões; Expresso - 2007-2015: 737 versões. Posteriormente, Diogo Cunha aprofunda o estudo, utilizando o sistema de pesquisa por endereço do Arquivo.pt para procurar os endereços dos websites dos quatro jornais em estudo até final do período em análise (de 01/01/1996 a 31/12/2016), tendo chegado aos seguintes valores: CM: 3128 versões; DN: 5568; Expresso: 4144; e Público: 8308 versões. Portanto, essa diferença abissal das 3166 versões dos websites dos jornais arquivados no Arquivo.pt para as 21148 versões detetadas das páginas principais dos websites dos quatro jornais com a atualização do estudo, mostra o nível da extensão e, portanto, quão complexos são os dados, as versões, atualizações, etc., e, portanto, o tipo de arquivo em análise. Ainda outro aspeto de relevante interesse tem a ver com a comparação entre os diferentes layouts que permitiu identificar algumas tendências gerais de desenvolvimentos dos websites em análise:

“As páginas web são cada vez mais extensas, sobretudo na vertical; (...) vão tendo progressivamente uma orientação verticalizada com grandes barras de scroll, embora sejam inseridos pequenos espaços com galerias ou pequenas barras de scroll; (...) vão apresentando um acréscimo de estabilidade estética, consolidando a identidade visual do jornal; as mudanças são cada vez mais difíceis de assinalar na medida em que deixa são gradualmente menos "macro" e mais "micro", o que implica uma certa adaptação da perspectiva de análise; vão surgindo cada vez mais imagens e vídeos, muitas vezes enquadradas em galerias, aumentam também o número de hiperligações, botões, menus e barras de scroll." (Cunha, 2017: 108).

Especificamente em relação à RTP online, do modelo "shovelware" e em "painel", relativo à primeira década do website, que basicamente reproduzia notícias e conteúdos de uma forma digamos "proto-digital", evoluiu-se para uma consolidação e maior coesão dos temas centrais dos conteúdos de serviço público em aspetos que consideramos decisivos na web: as questões da usabilidade, acessibilidade, diversidade, privacidade e arquivabilidade. Mas também no plano da solidariedade e da responsabilidade social. Era salvaguardada também, sobretudo nos últimos anos, a dimensão da herança cultural projetada no online através da abertura ao valioso espólio do Arquivo da RTP. Mas não basta arquivar conteúdos online: é essencial 
preservar toda a estrutura das páginas web em consonância com as WCAG e ter uma política de arquivo assertiva adequada aos princípios basilares do Internet Archive e ao Arquivo.pt. Do ponto de vista da UI/UX, a plataforma da RTP tem ainda campo para melhorar: da arquitetura da informação à experiência do utilizador há trabalho a fazer para ser mais percetível, operável, compreensível e robusta. E para ser ajustada aos princípios e da verificabilidade (fact checking) e da proporcionalidade (public value tests) (Ridinger, 2009; Svendson, 2011; Michalis, 2012; Moe and Donders, 2012; Page, 2015; IRIS, 2015; Castro e Freire, 2018; Cádima, 2019). Ainda a necessidade de reforço das questões de cidadania, satisfazendo as necessidades democráticas, sociais e culturais da sociedade, e de aprofundamento da divulgação do conhecimento e da difusão da herança cultural portuguesa e europeia. Neste ponto é fundamental o reforço da presença de conteúdos associados a programação cultural, ficção, séries e documentários de origem europeia. No fundo, importa consolidar o website da RTP e o seu potencial de transferência e disseminação do conhecimento com impacto social nos atores do sistema de media e na comunidade, procurando que seja acima de tudo um referente/regulador de boas práticas do sistema de media em Portugal.

\section{Por uma Política de Arquivo da Web}

Mas é o contexto da preservação que nos parece merecer uma maior atenção face aos dados disponibilizados. É um facto, de acordo com Diogo Cunha, que "o que hoje é notícia amanhã poderá estar esquecido", daí ser importante reter aquela sua conclusão como um alerta para toda a área Web portuguesa, em particular para o sector dos media online - é imperioso, de um ponto de vista da preservação deste património fundamental da web portuguesa que os média e muito em particular o serviço público de média, neste caso a RTP, dê o exemplo relativamente à aplicação de políticas - e práticas - de preservação de preservação digital estruturada e dedicada, sendo absolutamente certo, tal como refere Cunha (2017: 106) que a conceção e a ideia de que basta organizar a preservação de "conteúdos" não é adequada porque o essencial é preservar toda a estrutura das páginas web.

Uma coisa é, portanto, o Direito ao Esquecimento - o direito que todos devemos ter de apagar ou gerir os nossos dados pessoais na Internet, e esse começa a ser assegurado pelas políticas de privacidade dos websites em geral, reforçadas recentemente pelo RGPD - Regulamento Geral de Proteção de Dados, criado no âmbito da União Europeia, em vigor desde 25 de Maio de 2018. Outra coisa é a Web poder "cair no esquecimento", não ter o seu repositório, o seu arquivo global, isto é, não haver uma disposição específica semelhante à que existe para a privacidade, mas agora direcionada para a preservabilidade e a arquivabilidade. Ou seja, é imperioso 
evitar que uma parte importante do conteúdo da Web vá desaparecendo, ao sabor deste alegre "laisser faire" de postagens e de apagamentos de bytes ou de terabytes desta nossa contemporaneidade digital, sem apelo nem agravo.

Perder o arquivo e o rasto histórico da Web (Boran, 2019), seja o que o Facebook apaga de "fake news", ou toda a informação registada na plataforma Google + agora fechada, ou ainda, por exemplo, muita da "desinformação" apagada das redes sociais sobre as recentes Eleições europeias de 2019, ou outro qualquer conteúdo, real ou "fake", é perder uma parte vital do nosso património atual. É impedir o estudo desses mesmos fenómenos e a sua compreensão. É destruir a possibilidade de uma "arqueologia" da contemporaneidade.

Perguntar-se-á se o direito ao esquecimento não colide com o dever de arquivabilidade. Em matéria de direito à privacidade isso acontecerá certamente, mas tal como prescreve, por exemplo, o Regime Geral dos Arquivos e do Património Arquivístico (Arto 17으), haverá uma dilação temporal para um determinado tipo de documentos ou arquivos, nomeadamente os "nominativos", que contenham dados pessoais da esfera privada. Por exemplo, no caso do Arquivo Salazar, este tipo de documentos teve uma primeira dilação temporal de 50 anos (Decreto-Lei n.o 16/93), recentemente atualizada para 30 anos (Artigo 44. da Lei n.o 26/2016), permitindo o acesso mais cedo do que o esperado.

O problema da arquivabilidade da Web não tem tido, do nosso ponto de vista, a atenção que necessita, e que é cada vez mais urgente. Veja-se que a União Europeia se tem preocupado muito - e bem - com as políticas da privacidade e do direito ao esquecimento, mas não se preocupa com algo bem mais importante que é o facto de uma parte significativa dos conteúdos da Web ir caindo no esquecimento, ou desaparecer mesmo para sempre, criando uma espécie de Idade das Trevas digital que jamais se poderá resgatar.

Isto apesar dos esforços de algumas instâncias públicas ou privadas, como o Internet Archive, o Web Archivability Community Group, ou, no caso português, o Arquivo.pt, que têm procurado defender a honra do convento - mas não chega. A plataforma portuguesa de preservação da Web - o Arquivo.pt, disponibiliza formação e indicações concretas de como publicar informação na Web por forma a que seja preservada, ou sobre acesso e processamento automático de informação preservada da Web através de APIs, contribuindo assim para a disseminação do princípio da preservabilidade. Veja-se que nesta plataforma a única maneira de preservar conteúdos publicados em data anterior é obtendo-os a partir das entidades que os tenham guardado, isto porque a partir do momento em que um conteúdo deixa de estar disponível publicamente na Web torna-se impossível arquivá-lo. 
Mas importa ir mais longe neste desígnio. Deixo aqui, portanto um apelo aos historiadores da Web e da Internet, aos governos e à Comissão Europeia, para que se assuma este importante desafio no plano global no sentido de ser criada regulamentação específica, de âmbito europeu, sobre a matéria. Urge, portanto, uma iniciativa global por uma Política de Arquivo para a Web.

\section{Referências bibliográficas}

BASTOS, H. (2010): Origens e evolução do ciberjornalismo em Portugal. Porto: Edições Afrontamento.

BERNARDO, D. (2012): “As Televisões generalistas portuguesas online - Estudos sobre a presença de conteúdos informativos nos sites da RTP, SIC e TVI". Tese de Mestrado. Lisboa: ESCS.

BORAN, M. (25 de Abril de 2019): “Archiving the Net: 'Preserving the web isn't impossible". The Irish Times. Disponível em: https://www.irishtimes.com/business/technology/archiving-the-net-preservingthe-web-isn-t-impossible-1.3863450

BROADCASTING COMMUNICATION (2009): Communication from the Commission on the application of State aid rules to public service broadcasting (2009/C 257/01). https://eur-lex.europa.eu/legalcontent/EN/TXT/PDF/?uri=CELEX:52009XC1027(01)\&from=EN;

CÁDIMA, F. R. (2019): "Uma análise do website da RTP e os 'novos serviços audiovisuais' da televisão pública". In Cádima, F. R. (Org.). Diversidade $e$ Pluralismo nos Média. Lisboa: ICNOVA, pp. 93-108. http://www.icnova.fcsh.unl.pt/wpcontent/uploads/sites/38/2019/04/ICNOVA_Diversid_Plura_Analise.pdf -(2008): “Web TV local/regional em Portugal: Que alternativa à TV?". Anuário Internacional de Comunicação Lusófona. Comunicação e Cidadania, pp. 99-110. Universidade do Minho http://www.lasics.uminho.pt/ojs/index.php/anuario/article/view/745/666

- (2000): "Acessibilidade aos Conteúdos Públicos" in As Indústrias de Conteúdos Culturais em Portugal (Coord: Roberto Carneiro), Grupo Fórum, para os Ministérios da Cultura e da Economia, Lisboa.

CASTRO, M. R., e FREIRE, F. C. (2017): "The notion of public value in European public broadcasters: The cases of the United Kingdom, Austria and Germany," 2017 
12th Iberian Conference on Information Systems and Technologies (CISTI), Lisbon, 2017, pp. 1-6.doi: 10.23919/CISTI.2017.7976033

COMUNICAÇÃO DA CE (2001): Relativa à aplicação das regras em matéria de auxílios estatais ao serviço público de radiodifusão (2001/C 320/04). Jornal Oficial das Comunidades Europeias, 15.11.2001. Disponível em: https://eurlex.europa.eu/LexUriServ/LexUriServ.do?uri=OJ:C:2001:320:0005:0011:PT:PDF

CUNHA, D. (2017): Transformações da presença dos jornais portugueses na web (19962016): Correio da Manhã, Diário de Notícias, Expresso e Público Relatório final de um estudo de caso do projecto "Investiga XXI". FCT/FCCN. http://sobre.arquivo.pt/wp-content/uploads/ds_cunha_fccn_2017-1.pdf

DIAS, S. S. (2010): "Web TV - Análise e melhores práticas em OCS nacionais e internacionais". Tese de Mestrado. Lisboa: NOVA FCSH. Disponível em: http://hdl.handle.net/10362/6008.

DIRETIVA (2016): Diretiva (UE) 2016/2102 do Parlamento Europeu e do Conselho, de 26 de outubro de 2016 relativa à acessibilidade dos sítios Web e das aplicações móveis de organismos do setor público. Disponível em: http://www.acessibilidade.gov.pt/publicacoes/diretiva2016-2102

ERC (2014): "ERC recomenda as WCAG 2.0 aos Operadores de Televisão". Deliberação 4/2014. Disponível em: http://www.acessibilidade.gov.pt/arquivo/1054

ESTUDO SOBRE A RECEÇÃO DE AUDIODESCRIÇÃO TRANSMITIDA PELA RTP (2016): Unidade ACESSO do DSI da FCT. Disponível em: http://www.acessibilidade.gov.pt/estudos/2016_estudo_audiodescricao.pdf

FERNANDES, J. (2011): “Os Media Portugueses na Internet: Acessibilidade dos conteúdos Web da imprensa escrita, radiofónica e televisiva segundo as WCAG 1.0 do W3C". UMIC, Setembro de 2011. Disponível em: http://www.acessibilidade.gov.pt/media/media_internet.doc

GRANADO, A. (2002): "Os media portugueses na Internet". Disponível em: http://ciberjornalismo.com/mediaportugueses.htm

IRIS SPECIAL (2015): Online activities of public service media: remit and financing. Strasbourg: European Audiovisual Observatory. Strasbourg: OEA. Disponível em: https://book.coe.int/en/european-audiovisual-observatory/6725-iris-specialonline-activities-of-public-service-media-remit-and-financing.html

MICHALIS. M. (2012): Assessing the British Public Value Test: Benefits, limitations and challenges ahead. International Journal of Media \& Cultural Politics, Volume 8, Number 1, 23 April 2012, pp. 13-30(18). 
MOE, H. and DONDERS, K. (Eds.) (2011): Exporting the Public Value Test The Regulation of Public Broadcasters' New Media Services Across Europe. University of Gothenburg: Nordicom.

PAGE, M. F. (2015): The development of BBC on-demand strategy 2003-2007: the Public Value Test and the iPlayer. PhD thesis. http://theses.gla.ac.uk/6779/1/2015floodpagephd\%20.pdf

RAPOSO, C. (2017): "Estado e sociedade na era da internet em Portugal - acessibilidade dos sítios na web do Governo e das instituições públicas em 2015". Tese de Mestrado em Novos Media e Práticas Web. Lisboa: NOVA FCSH. Disponível em: http://hdl.handle.net/10362/20710

RIDINGER, M. (2009): "The Public Service Remit and the New Media", IRIS plus, supplement to IRIS, Legal Observations of the European Audiovisual Observatory, Issue 2009-6, Strasbourg. http://www.obs.coe.int/documents/205595/264587/IRIS+plus+2009en4LA.pdf/3 febdb44-89f8-452a-98fc-fa63067e5452.

SOARES, T. M. (2006): Cibermedi@ - Os Meios de Comunicação Social Portugueses Online, Lisboa: Escolar Editora.

SCHULTZ, T. (1999): "Interactive Options in Online Journalism: A Content Analysis of 100 U.S. Newspapers". Journal of Computer-Mediated Communication. Volume5, Issue 1 September $1999 . \quad$ Disponível em: http://jcmc.indiana.edu/vol5/issue1/schultz.html (01-09-2006).

SVENDSON, E. (2011): "Two Steps Towards a Public Value Test. Danish Public Service Broadcasting Between Two Lines of Control". In Moe, Hallvard and Donders, Karen (Eds.) (2011). Exporting the Public Value Test The Regulation of Public Broadcasters' New Media Services Across Europe. University of Gothenburg: Nordicom, pp 117-126.

ZAMITH, F. (2008): Uma Proposta Metodológica para analisar o Aproveitamento das Potencialidades Ciberjornalísticas da Internet. Observatorio (OBS*) Journal, 2 (2), 165- 191. http://obs.obercom.pt/index.php/obs/article/view/109/154

\section{Websites:}

AccessMonitor: http://www.acessibilidade.gov.pt

Arquivo.pt: http://arquivo.pt/

Internet Archive: https://archive.org/ 
Web Content Accessibility Guidelines (WCAG): https://www.w3.org/WAI/standardsguidelines/wcag/ 